\title{
Políticas y poéticas de la memoria y del patrimonio cultural afrocubano: el caso del Central Azucarero México
}

\author{
Politics and Poetics of Afrocuban Memory and Cultural \\ Heritage: The Case of the Central Azucarero México
}

\author{
Milena Annecchiarico* \\ Universidad de Buenos Aires-Conicet
}

\begin{abstract}
$\overline{\text { RESUMEN }}$
Este artículo presenta una experiencia de gestión comunitaria del patrimonio cultural afrocubano en el Central Azucarero México, ubicado en la provincia de Matanzas (Cuba). Se analizan las articulaciones entre memoria colectiva, política cultural y racialidad que operan en la definición y gestión de los bienes comunes patrimoniales en el contexto cubano actual. Teniendo en cuenta las dinámicas históricas, culturales y políticas de la comunidad, se destaca que la activación de demandas de visibilidad y de organización autonómica en la gestión del patrimonio permite la emergencia de una narrativa local que reubica el pasado esclavista en el marco de las necesidades y expectativas actuales, que incluyen la lucha antirracista.
\end{abstract}

Palabras clave: patrimonio cultural afrocubano, memoria colectiva, políticas culturales, cuba.

\begin{abstract}
$\overline{\text { ABSTRACT }}$
This article presents an experience of community management of Afrocuban cultural heritage in the Central Azucarero México, located in the province of Matanzas (Cuba). I analyze the articulations between collective memory and cultural and racial politics that operate in the definition and management of common heritage goods in modern day Cuba. Keeping in mind the historical, cultural, and political dynamics of the community, what stands out is the activation of demands for visibility and the autonomous organization of heritage management which enable the emergence of a local narrative that relocates the slave past in the framework of current needs and expectations, including the fight against racism.
\end{abstract}

Keywords: Afrocuban cultural heritage, collective memory, cultural politics, Cuba.

Doctora en Antropología de la Universidad de Buenos Aires. Es investigadora en el Instituto de Ciencias Antropológicas de la misma universidad y becaria posdoctoral del Consejo Nacional de Investigaciones Científicas y Técnicas. Se especializa en el estudio de las dinámicas culturales y políticas de los pueblos afrodescendientes. Su artículo más reciente es "La africanía y la cuestión racial en los estudios afrocubanos”, Tábula Rasa 27 (2017): 249-271. 


\section{Introducción}

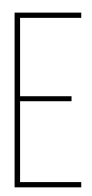

ste artículo propone analizar una experiencia de gestión comunitaria del patrimonio cultural afrocubano del Central Azucarero México (en adelante Central México), conocido también con el antiguo nombre colonial de Ingenio Álava, ubicado en la provincia de Matanzas, $\mathrm{Cuba}^{1}$. De acuerdo con los resultados de mi investigación doctoral (2016), me interesa abordar algunas problemáticas relativas a la construcción de la memoria colectiva y las formas de gestión del patrimonio cultural local, examinando las articulaciones entre memoria, patrimonio y racialidad (Gilroy 2003; Halbawchs 2011; Hall 2010; Pollack 1989; Wade 2010). El marco teórico metodológico se basa en la aplicación y revisión crítica de perspectivas desarrolladas en las últimas décadas por la antropología en relación con la cultura, la identidad, la etnicidad y la racialidad, así como en reflexiones de los procesos hegemónicos y contrahegemónicos de saberes, prácticas y usos del pasado de la africanía en nuestro continente (Gilroy 2003; Lao-Montes 2007; Restrepo 2004; Segato 2007; Wade 2010).

El proyecto comunitario del Central México "Tras las huellas de nuestros ancestros” (en adelante THNA) emerge como un actor clave en la gestión del patrimonio en cuanto bien común ${ }^{2}$. Las acciones y evaluaciones que los miembros del grupo THNA emprenden para el rescate y la valorización de la historia local y de las prácticas culturales existentes revelan disputas y tensiones en la construcción de una memoria colectiva que dé cuenta del pasado común de opresión y emancipación protagonizado por los africanos esclavizados y sus descendientes. También reivindican el protagonismo y la agencia de los propios sujetos en estos procesos, haciendo visibles las tensiones racializadas en el campo de la cultura y del patrimonio. Las dinámicas históricas, sociales y antropológicas de la comunidad del Central México configuran entonces un disputado espacio de la cultura y de la memoria como canalizador de sentimientos de pertenencia y construcción de identificaciones colectivas antihegemónicas y potencialmente decoloniales.

1 Agradezco a todas las personas que colaboraron en la investigación en la que se basa el artículo, especialmente, a los habitantes del Central Azucarero México y a los coordinadores del proyecto "Tras las huellas de nuestros ancestros", cuyas voces son centrales en este ensayo. Una versión preliminar de este escrito fue presentada en el II Congreso Internacional los Pueblos Originarios de América Latina, siglos XIX-XXI (Cipial), UNLPam, Santa Rosa, del 20 al 24 de septiembre del 2016.

2 No profundizaré aquí en la noción de bienes comunes. Me interesa por ahora citar a Lafuente y Corsín (2012), quienes los definen como bienes compartidos cuya circulación está regulada por la economía del don. 
En este trabajo propongo un recorrido analítico por las experiencias de valoración y gestión comunitaria del patrimonio, desarrolladas por el proyecto THNA, a partir del trabajo de investigación y recopilación de historias orales y artefactos histórico-culturales realizado por sus miembros y liderado por los hermanos Eneida y Anselmo Villegas Zulueta. Estas acciones confluyen en la creación de la sala museo comunitaria Ma’ Carlota, que estudiaremos de manera más específica en el artículo.

El estudio propone algunos resultados de la investigación realizada entre el 2012 y el 2015 para mi tesis doctoral, siguiendo una metodología etnográfica relacional y participativa basada en el trabajo de campo, el registro y la aplicación de entrevistas, así como en el análisis bibliográfico y de fuentes documentales (Annecchiarico 2016). De acuerdo con una perspectiva antropológica atenta a la experiencia y a la agencia de los sujetos, este artículo explora las conexiones entre las distintas dimensiones de un fenómeno sociocultural, desentrañando las modalidades de la disputa simbólica en relación con las memorias, las identidades y sus usos políticos (Bourdieu 1992). De esta manera, considero la experiencia de significación y gestión del patrimonio local en tanto locus de enunciación de los sujetos, con políticas culturales y culturas políticas específicas, construidas y lideradas por la comunidad. Finalmente, el trabajo apunta a considerar la africanía o afrodescendencia en Cuba como experiencias situadas geohistóricamente de la diáspora africana en las Américas ${ }^{3}$.

El artículo comienza con la exposición de algunos debates que intervienen en el campo cultural afrocubano en relación con los cruces entre nación, memoria y raza; se indagan las trayectorias de las políticas culturales en temas afro, especialmente las activaciones patrimoniales inherentes al legado de la esclavitud luego de los años noventa en la provincia de Matanzas. Después, presento el Central Azucarero México, a partir de un análisis de la conformación sociocultural y geohistórica de la comunidad. Analizo un evento performático que pone en escena experiencias del pasado esclavista y que introduce la temática objeto del estudio. El análisis etnográfico se centra entonces en la trayectoria del proyecto

3 No me detendré en el análisis conceptual de la africanía y de la afrodescendencia y sus usos en el contexto cubano, términos que utilizo en el presente artículo, que tienen trayectorias y significados específicos; sobre ello he escrito en otros trabajos (2015, 2016, en prensa). Es suficiente considerar aquí que ambos términos aluden a la diáspora africana en las Américas y a sus múltiples transculturaciones y resignificaciones políticas y epistemológicas. Sin embargo, en términos generales, empleo africanía para referirme a los aspectos culturales e históricos de la presencia africana en Cuba y afrodescendencia como término étnico-racial y político-cultural para hablar de las personas que en Cuba se consideran (en términos emic) negras o mulatas. Al respecto, cabe señalar que el término afrodescendiente es usado en Cuba por ciertos sectores intelectuales y del activismo como parte del actual proceso de visibilización afro en Latinoamérica y el Caribe. 
THNA y la experiencia de gestión de la sala comunitaria. El artículo finaliza con una reflexión sobre los usos del patrimonio y de la memoria en el contexto analizado, proponiendo pistas para articular los estudios de la presencia africana en Cuba y la opción decolonial en tanto enfoque crítico contemporáneo en las ciencias sociales.

\section{Africanía, políticas culturales y cuestión racial}

Algunos autores cubanos contemporáneos argumentan una convergencia entre postulados ideológicos del proyecto revolucionario cubano y cuestiones identitarias nacionales (Barnet 1998; Guanche 2002). Según estas lecturas, la "herencia africana" o las "huellas de africanía" se identifican con una historia nacional de resistencias y rebeldías desde la época colonial, en la cual los africanos y los afrocubanos desempeñaron un papel central, bien como esclavizados y subalternos, bien como cimarrones y luchadores en el proceso de liberación nacional (M. Fernández 2005; Ferrer 2011)4. Al respecto, la historiadora cubana Ada Ferrer analiza el movimiento nacionalista durante las guerras de independencia (1868-1898), en las que tuvieron un fuerte protagonismo los africanos esclavizados; la autora considera que ese movimiento se caracterizó por luchas y retóricas antirracistas, que desafiaban los "dogmas de la teoría racial noratlántica y también diferían del pensamiento racial imperante en las antiguas colonias españolas y portuguesas" (Ferrer 2011, 9). Por otro lado, la incorporación de ciertas identidades en la nación -incluyendo las ligadas a prácticas culturales afrocubanas- ha sido objeto de conflictos históricos de larga duración. De acuerdo con la intelectual cubana Zuleica Romay, luego de la Independencia el proceso de construcción nacional fue violento y ambivalente, especialmente para los sectores negros. Abolida la esclavitud, el país se convirtió para ellos en "una gigantesca plantación" (Romay 2015, 33). La abolición no contribuyó por sí misma ni a la emancipación social y económica de los exesclavizados y sus descendientes, ni a la inclusión de sus prácticas culturales en las narrativas hegemónicas de nación. Las relaciones de poder basadas en la violencia —fáctica y simbólica—fueron recodificadas de

$4 \quad$ El concepto de africanía o afrocubanía fue formulado por Fernando Ortiz en sus primeros trabajos y es objeto de análisis reiterado en su obra (Ortiz [1950] 2001). Cabe destacar además su contribución al concepto de transculturación en el Contrapunteo cubano del tabaco y el azúcar ([1940] 1963), que resume y sustenta sus propuestas al respecto (Annecchiarico 2017). 
acuerdo con los contextos históricos, es decir, sobrevivieron y se transformaron según "mutaciones adaptativas” hasta el presente (Romay 2015, 41). El mestizaje y el blanqueamiento como ideologías nacionales de las repúblicas latinoamericanas, en Cuba también fueron funcionales a la resignificación de las relaciones de subordinación marcadas por la clase social, la raza y el género, a la vez que las fracturas racializadas se profundizaron y se reconfiguraron bajo un nuevo orden social ${ }^{5}$.

Como he analizado en otro trabajo (Annecchiarico 2015), la revolución de 1959 fue un movimiento de ruptura radical, con ambivalencias, conflictos, continuidades y cambios significativos. Los nuevos discursos de nación se articularon alrededor de dos directrices principales: por un lado, consolidaron la idea de mestizaje desracializado que había sido central en el pensamiento de las décadas anteriores, avalando los postulados decimonónicos que proponían una nación sin blancos ni negros, sino con cubanos (Ferrer 2011). Esta postura se radicalizó bajo los principios marxistas que suponían que, al eliminar la clase social como principal factor de desigualdad socioeconómica, se eliminaría todo tipo de discriminación, incluyendo la racial, obturando el debate público sobre la persistencia del racismo y las problemáticas sociorraciales no resueltas (Colectivo de autores 2011; Matos 2012; Morales 2012; Zurbano 2012).

Por otro lado, sostengo que el principal cambio epistemológico de la Revolución cubana con respecto a la cuestión afrocubana consiste en una reubicación de la llamada cultura popular, principalmente afrocubana, en tanto objeto-sujeto de los discursos ideológicos e intelectuales del nuevo orden social. La narrativa revolucionaria posicionó a los africanos y sus descendientes como antepasados culturales-revolucionarios en dos sentidos: por su legado cultural, es decir, la africanía de la música y las artes, las religiones, el idioma y la comida; y por su historia de emancipación y de luchas anticolonialistas del siglo XIX (Annecchiarico 2015) .

Para analizar de manera crítica la relación entre los usos de la africanía, el poder y la racialidad, me parece útil considerar que la política cultural es una dimensión clave en la producción y regulación de las identidades nacionales (García Canclini 1987; Yúdice y Miller 2002), en tanto que la cultura es una "trama donde se producen disputas cruciales sobre las desigualdades, sus legitimidades

Para profundizar, sugiero la lectura del célebre ensayo del destacado pensador afrocubano Walterio Carbonell ([1960] 2006), uno de los primeros intelectuales marxistas críticos que discute los cánones elitistas de la historiografía sobre la formación de la nación cubana, reivindicando la participación de los africanos esclavizados y sus descendientes. 
y las posibilidades de transformación” (Grimson 2011, 41). En relación con los procesos de conformación de las identidades nacionales, Yúdice y Miller subrayan la centralidad de las políticas culturales en tanto políticas de gubernamentalidad del Estado, mediante las cuales se produce legitimidad para garantizar los intereses de la nación (2002). Según estos autores, la política cultural, con todos sus medios disponibles - la enseñanza, la lengua, los medios de comunicación, las artes, etc.- - constituye un terreno privilegiado para construir hegemonía y promover la unidad cultural nacional, pero a la vez y sobre todo representa un campo de disputas y de conflictos en donde los sectores subalternos despliegan sus reivindicaciones, en las contingencias históricas y contextuales específicas (2002). Por ello, la política cultural no debe ser entendida únicamente como ámbito público gestionado por las instituciones estatales creadas ad hoc, como ministerios de cultura, planes nacionales de cultura, agencias gubernamentales, entre otros. Al contrario, para comprender cómo funcionan las dinámicas entre cultura, poder y diferencia es necesario considerar la política cultural como una arena heterogénea de disputas en la que actúan sujetos desde diferentes posiciones y demandas, con (auto)representaciones sociales, necesidades, experiencias y objetivos políticos específicos (Crespo, Losada y Martín 2015).

A lo largo de las cinco décadas de Revolución cubana ha sido puesta en marcha una política de valorización y rescate de las "huellas de africanía” que conforma escenarios de disputas sobre los sentidos de la experiencia negra a partir de una pluralidad de actores: artistas e intelectuales, activistas y funcionarios públicos (Annecchiarico 2015). En el marco de las políticas nacionales de rescate y valoración de la cultura popular, que incluían principalmente las tradiciones afrocubanas, se crearon diferentes grupos folclóricos con el objetivo de recuperar y difundir las expresiones artísticas, musicales y dancísticas, en su mayoría provenientes de los diferentes sistemas religiosos afrocubanos. No obstante, considero que estas políticas centradas en la cultura traen consigo una perspectiva demasiado culturalista y no permiten enfocar la cuestión racial que, por el contrario, también se configura como un campo de lucha crucial en la arena de los derechos culturales (Escobar 2005).

Algunos intelectuales cubanos contemporáneos ponen de relieve la persistencia de un legado colonial eurocéntrico en la memoria histórica nacional que, según las palabras de un reconocido ensayista, Tato Quiñones (2009), "no ha podido independizarse de un canon patriótico eurocéntrico" a pesar de la narrativa emancipadora en la que se inscribe la Revolución cubana. Por otro lado, Carlos Moore (2008), muy crítico del sistema político cubano, habla del fracaso del proyecto revolucionario en términos de lucha antirracista. El autor argumenta 
que el gobierno instaurado en 1959 adoptó la ideología hegemónica blanca, la cual sigue intacta como epistemología hegemónica, porque no pasó por la experiencia histórica de una contrahegemonía no blanca: no pudo conformarse un partido negro bajo el sistema socialista; todas las experiencias que apuntaban a esa dirección fueron sofocadas ${ }^{7}$. Es posible entonces considerar las ambivalencias del discurso y de la experiencia revolucionaria que, si bien se inscribe como proyecto anticolonialista y antiimperialista de vasta proyección, conserva profundas huellas de colonialidad, principalmente con respecto a la temática racial.

De acuerdo con estas discusiones, me interesa ver cómo se conjugan diferentes narrativas de la africanía con las acciones de política cultural, lo cual nos permitirá luego ubicar mejor el análisis de la experiencia de gestión del patrimonio en el Central México. Considero que el campo cultural es un espacio interesante donde observar estas problemáticas, por cuanto allí "se dan las grandes batallas ideológicas, económicas y políticas de hoy” (Zurbano 2012), mientras que en las instituciones públicas especializadas persiste una visión reductora de la cultura, burocrática y apolítica, considerada un espacio insuficiente para discutir y resolver las problemáticas raciales (Zurbano 2012, 267). Este artículo evidencia las ambivalencias entre diferentes modos de significar y gestionar el patrimonio cultural afrocubano y las tensiones entre los diferentes actores involucrados en los usos de la cultura y de la memoria. Me interesa ver cómo se movilizan determinados recursos culturales relacionados con la presencia africana y la esclavitud y qué tensiones aparecen entre los diferentes actores sociales.

$7 \quad$ Esta afirmación es inexacta, ya que existen diferentes organizaciones y espacios de activismo afrocubano. Para citar los más destacados, en 1998 se creó en La Habana la Cofradía de la Negritud, liderada por el reconocido activista y pensador afrocubano Norberto Mesa Carbonell, un movimiento de la sociedad civil que se propone discutir y visibilizar la vigencia del racismo. También en La Habana, en el 2012 se conformó la Articulación Regional Afrodescendiente para las Américas y el Caribe (Araac), una red transnacional independiente que reúne a líderes, activistas e intelectuales afrodescendientes. En el mismo año, siempre en La Habana, comenzó sus actividades la Red Barrial Afrodescendiente, que trabaja con comunidades de barrios marginales, capacitando a líderes locales sobre el racismo y realizando talleres artísticos y culturales dirigidos especialmente al empoderamiento de las mujeres afrodescendientes. Sobre estas experiencias véase Annecchiarico (2016). 


\section{Trayectorias locales de promoción del patrimonio cultural inmaterial $(\mathrm{PCl})$}

En Matanzas, ciudad y provincia, se fueron conformando a partir de los años noventa nuevas experiencias de trabajo sociocultural comunitario, con proyectos artísticos y educativos vinculados a prácticas y expresiones culturales afrocubanas arraigadas históricamente en el territorio. Por otro lado, con el impulso del programa de la Unesco La Ruta del Esclavo y su comité nacional, a finales de los noventa y comienzos de la década del 2000, se restauró el Castillo de San Severino que hoy funciona como museo y sede del programa a nivel regional. En Cuba, y especialmente en Matanzas, la llegada de La Ruta del Esclavo significó además la profundización y circulación de diferentes experiencias de trabajo comunitario ya en marcha, mientras otras se fueron creando con vistas a salvaguardar y promover el rico acervo de religiones y expresiones culturales afrocubanas, generalmente incluidas bajo la denominación de patrimonio cultural inmaterial ${ }^{8}$. El comité nacional de La Ruta del Esclavo realizó un registro de patrimonio a escala nacional que incluye las casas templo de las religiones afrocubanas, las ruinas de ingenios y cafetales, los barracones y demás sitios de memoria vinculados con la presencia africana. Se registraron 728 sitios relacionados con la esclavitud, la trata y la diáspora africana, según las “evidencias materiales” requeridas por la Unesco; muchos de ellos se encuentran en Matanzas. Además, en línea con la Convención para la Salvaguardia del PCI del 2003 y la Convención sobre la Protección y Promoción de la Diversidad de las Expresiones Culturales del 2005, se identificaron nueve sitios de memoria "donde se combinan por primera vez el patrimonio edificado o el natural con el patrimonio cultural vivo, también denominado en diversos documentos y contextos como 'patrimonio cultural inmaterial' o 'patrimonio cultural intangible”' (Guanche 2006, 1).

Estas experiencias, promovidas y posibilitadas en diferentes medidas por el Estado cubano, actualizan y reivindican el legado histórico y cultural africano presente en el territorio. En efecto, luego de una disminución del interés por las temáticas afrocubanas o raciales por parte de las agencias estatales entre los años setenta y finales de los ochenta — que se refleja en la ausencia de investigaciones y de producción de conocimiento al respecto para esa época-, a partir de monio Cultural Inmaterial (PCI): la Tumba Francesa de Santiago de Cuba (2008) y la rumba (2016). Sin embargo, todas las expresiones culturales reconocidas como "tradiciones afrocubanas", que incluyen prácticas dancísticas, musicales y religiosas, son valoradas localmente como patrimonio cultural, cuenten o no con reconocimientos oficiales. 
mediados de los noventa se viabilizan nuevas acciones y estrategias de promoción de la diversidad cultural y de reapertura del debate en torno a la cuestión racial ${ }^{9}$.

Entre la década de los noventa y del 2000, de forma paralela al comienzo de las políticas de patrimonialización y salvaguardia de las expresiones culturales afrocubanas, emerge una narrativa de la negritud, principalmente en la producción literaria y artística, que se configura como un espacio de identificación de prácticas sistemáticas de injusticia no resueltas definitivamente por las políticas socialistas (Valero 2011). Así, la agenda pública y la investigación científica se actualizan en enfoques y miradas a partir de las experiencias de comunidades, escritores, artistas e intelectuales afrodescendientes (Zurbano 2012). En este escenario, operan los institutos de patrimonio y cultura nacionales y provinciales, entre ellos la Dirección de Patrimonio y las casas de cultura, órganos del Ministerio de Cultura, junto a institutos de investigación y promoción de las expresiones afrocubanas ${ }^{10}$. Al mismo tiempo, los organismos internacionales también intervienen en el campo de las políticas culturales cubanas vinculadas con la presencia africana, relaciones que resultan particularmente significativas para el caso en consideración. Entre ellos, además de la Unesco — cuya sede regional para América Latina y el Caribe se encuentra en La Habana-, tiene un papel significativo el Centro Regional para la Salvaguardia del Patrimonio Cultural Inmaterial de América Latina (Crespial), con sus programas de salvaguardia del patrimonio cultural inmaterial que, como veremos, tuvieron mucha trascendencia en el Central México.

La trayectoria del grupo de trabajo sociocultural THNA del Central México refleja de modo ejemplar estos procesos y transformaciones de las políticas culturales hacia la cuestión afrocubana, demostrando un interesante cruce con las políticas raciales. En efecto, el grupo THNA hace un uso estratégico de las

El investigador estadounidense Marc Sawyer (2006) habla de ciclos de apertura y de clausura en las políticas raciales cubanas a lo largo del siglo XX, focalizando su análisis en los noventa. $\mathrm{El}$ autor observa que con la crisis socioeconómica ocurrida en la isla luego del derrumbe del campo socialista, la ideología racial afloró con fuerza en el sector privado - principalmente en el turismo y la prostitución-, mientras se agudizó en las relaciones interpersonales, así como en las estructuras laborales y en las relaciones de trabajo. Al mismo tiempo, otros investigadores, entre los cuales me incluyo, dan cuenta para esa misma época de una apertura en los debates intelectuales y del activismo negro respecto de la cuestión racial, así como de la puesta en marcha de agendas políticas de promoción de la presencia africana en diferentes escalas (Annecchiarico 2017; Fernández 2012; Morales 2012; Valero 2011; Zurbano 2012).

10 Mi investigación doctoral se detiene en el análisis de las acciones de la Casa de África de La Habana, institución que pertenece a la Oficina del Historiador de la Ciudad y que desde mediados de los noventa protagoniza proyectos de gestión cultural y difusión de resultados de investigaciones relacionados con la presencia africana en el país. Véase Annecchiarico (2015, 2016). 
herramientas disponibles a escala local e internacional, en su interacción con el Estado socialista (órganos estatales de cultura y patrimonio, universidades, instituciones y asociaciones culturales) y con las agencias internacionales de cultura. Teniendo en cuenta las dinámicas históricas, culturales y políticas de la comunidad, entiendo que la activación de demandas de visibilidad y de organización autonómica en la gestión del patrimonio, en tanto bien común, permite la emergencia de una narrativa local que reubica el pasado esclavista en el marco de las necesidades y expectativas actuales, que incluyen la lucha antirracista.

\section{El Central Azucarero México}

Yo soy también el nieto, bisnieto, tataranieto de un esclavo (que se avergüence el amo). Nicolás Guillén ([1979], 1996), fragmento del poema “El apellido”

Unos niños juegan baloncesto en un campito al lado de las ruinas de la casa del antiguo dueño del ingenio, don Julián Zulueta. En un costado de la fachada sin techo se percibe un rótulo casi borrado por el tiempo y cubierto por enredaderas; en la pared lateral se lee en letras grandes: "Ruinas de la casa de Julián Zulueta y Amondo, 1850” (figura 1). Asomándonos un poco más se entrevén algunas viviendas, sogas con ropa colgando al sol, que aparecen en lo que era el salón de la antigua casa colonial y que hoy es un silencioso y soleado patio compartido y un pasaje hacia las casas del fondo. Frente a la casa, a un costado del campito de juego, se encuentran una gran rueda y la caldera de la época de los estadounidenses, que funcionaron en el ingenio hasta hace pocos años. Del otro lado de la calle y de la plaza central, la planta del central azucarero se erige en toda su imponencia, con sus altas chimeneas fumantes, los camiones con la caña esperando para descargar y las calderas a todo vapor las veinticuatro horas del día. Es el 31 de diciembre y todo el pueblo está festejando porque va a comenzar la zafra ${ }^{11}$. Frente al central se encuentra la plaza con su reloj de sol y su glorieta de troncos de árboles. Del otro lado de la plaza y de cara al central está la torre campanario, desde donde se accede a lo que fue el barracón y hoy son viviendas ocupadas

11 La zafra es el trabajo de recolección de la caña de azúcar y la actividad industrial de fabricación del azúcar; indica también el periodo en que se realizan estas actividades que en Cuba van de enero hasta mayo aproximadamente, época de invierno. 
principalmente por las familias afrodescendientes, construidas en su mayoría luego de la demolición parcial del barracón en los años setenta ${ }^{12}$.

Figura 1. Campito de juego frente a las ruinas de la casa de Julián de Zulueta y Amondo, Central Azucarero México, enero del 2012

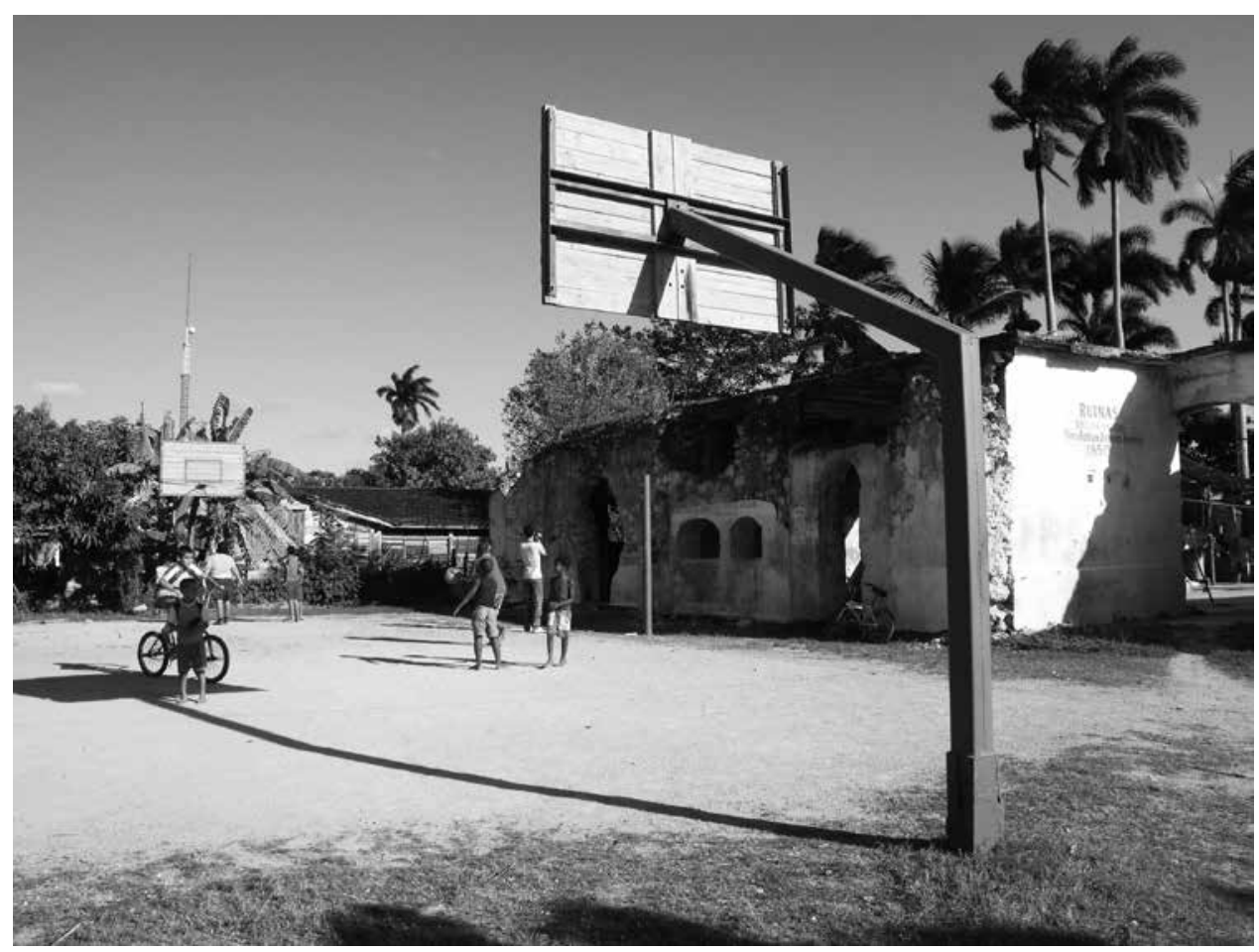

Fuente: elaboración propia.

El Central Azucarero México es un pequeño poblado rural o batey de la provincia de Matanzas, en el municipio de Colón, fundado el 21 de agosto de $1836^{13}$. Está ubicado en la campaña matancera caracterizada por amplios cañaverales e ingenios azucareros, algunos en ruinas o transformados en museo, y otros, como en este caso, aún activos. Limita al norte con la costa atlántica, el puerto de Cárdenas y el polo turístico de Varadero, y al sur, con la ensenada de

12 Esta descripción corresponde a las observaciones de campo realizadas entre diciembre del 2014 y enero del 2015.

13 A lo largo del texto emplearemos ambas denominaciones, México y Álava, aclarando que el primero es el nombre actual, mientras que Álava es el nombre colonial, oficialmente abandonado desde los años sesenta, pero que se mantiene en el uso local, en referencia al pasado colonial y con un sentido identitario, como he podido observar en mis estadías. Por otro lado, el nombre de "México" aparece localmente y en las fuentes consultadas como "Méjico". 
Cochinos y la ciénaga de Zapata. A pesar de su cercanía a uno de los principales corredores turísticos que conecta la ciudad de La Habana con Varadero, la comunidad del batey se encuentra aislada de estos circuitos, lo cual es señalado por los habitantes como un factor que afecta fuertemente el desarrollo local y las conexiones con otros centros.

Matanzas es heredera histórica y cultural del esplendor económico y productivo colonial basado en la industria azucarera, llamada la Atenas de Cuba por la actividad artística y literaria que la caracterizó durante el siglo XIX y comienzos del XX. En efecto, es la provincia del occidente con la mayor presencia de sitios de memoria asociados a la esclavitud y al cimarronaje y de expresiones culturales afrocubanas. Fue tierra de sublevaciones y rebeldías; la más célebre es aquella protagonizada por la africana esclavizada Carlota, del Ingenio Triunvirato, no lejos del Ingenio Álava, en donde hoy se erige el Monumento al Esclavo Rebelde (Franco [1978] 2011) ${ }^{14}$.

El Ingenio Álava se destaca en esta región por diferentes razones. El dueño más célebre fue el hacendado Julián de Zulueta y Amondo, conocido en los libros como el "Rey del Azúcar” y como “don Julián Zulueta” por los habitantes actuales del batey ${ }^{15}$. Fue uno de los ingenios azucareros más productivos de la época colonial tardía, gracias a las innovaciones de producción capitalista introducidas por Julián de Zulueta — calderas a vapor, sistemas de ferrocarril hasta los puertos de Cárdenas y de La Habana-, y sobre todo porque contaba con la dotación más grande de africanos esclavizados — principalmente del grupo étnico yoruba- y de chinos culíes (Marrero 2006) ${ }^{16}$. Sobre don Julián Zulueta circulan en el batey numerosos relatos que lo retratan, por un lado, como una persona muy emprendedora y muy hábil en sus negocios (Pedro Díaz del Castillo, entrevista, Central México, diciembre del 2014). Por otro lado, abundan las anécdotas sobre su crueldad con los esclavizados, no solamente en relación con las condiciones de

En honor a Carlota, se llamó “Operación Carlota” la participación militar cubana durante la guerra civil de Angola en 1975. En 1991 el expresidente de Sudáfrica Nelson Mandela visitó Cuba y desde Triunvirato recordó las profundas relaciones que unen a Cuba y África; luego de su visita, se erigió el Monumento al Esclavo Rebelde que hoy se encuentra en la localidad.

Julián de Zulueta y Amondo fue uno de los mayores esclavistas españoles y exponentes de la llamada "oligarquía negrera" de la isla. Fue gobernador de La Habana e impulsor del capitalismo del último periodo de la Colonia, antiindependentista. También fue dueño del Ingenio Álava y de otros de la región durante la última etapa colonial (Franco 1980; Moreno [1974] 2001). En el texto emplearé las formas abreviadas de Julián de Zulueta o don Julián Zulueta, como es llamado localmente. contratada para trabajar en la caña de azúcar y convivieron con los esclavizados negros. El término culí proviene probablemente del vocablo inglés coolie o kuli con los que se denominaba a los chinos contratados por las colonias inglesas (Valdés 2000, 55). 
trabajo esclavo en todo el proceso de producción azucarera, desde los campos de caña hasta el ingenio. Según los pobladores actuales, Julián de Zulueta fue un "hombre muy malo, de látigo, terrible", culpable de todos los crímenes más feroces que cometía contra la población negra, desde la violencia sexual hacia las mujeres hasta los regímenes de castigo ejemplar para quienes se rebelaban a su condición de esclavizado (Anselmo Villegas Zulueta, entrevista, Central México, diciembre del 2014).

En el batey residen actualmente alrededor de 3.000 personas, afrodescendientes en su mayoría, o, según las categorías locales, negra y mestiza/mulata, en continuidad con las transformaciones de la estructura poblacional colonial y republicana ${ }^{17}$. Muchos habitantes llevan hoy el apellido Zulueta, testimonio familiar del pasado esclavista. Eneida Villegas Zulueta me explica que "hay tantos Zulueta porque don Julián le impuso su apellido a todos los negros que vivían aquí, sean familia o no. Por tal motivo existe una gran cantidad de Zulueta y de Zulueta Zulueta que no son familia” (Eneida Villegas Zulueta, entrevista, Central México, diciembre del 2015) ${ }^{18}$.

En la época colonial, en el barracón vivían los esclavizados al lado del cuarto de los mayorales y contramayorales (Moreno [1974] 2001) ${ }^{19}$. Una torre campanario en la entrada del barracón marcaba las horas de la faena. Una de las características del batey es la conservación casi total de la estructura del barracón y su reubicación funcional para viviendas. Hoy en día se emplea el término el barracón como si se tratara de un barrio, el casco histórico, para diferenciarlo de las otras áreas del batey. La estructura habitacional del batey del Ingenio Álava fue cambiando notablemente a lo largo del siglo XX de acuerdo con el aumento de su población, principalmente debido a la migración interna movilizada por la industria azucarera. En el Ingenio Álava, Julián de Zulueta tenía una casona de dos pisos en donde vivía durante sus estadías. Los únicos blancos que moraban en el ingenio eran, además de don Julián,

El $68 \%$ de los pobladores del batey son negros y mestizos, cifra que contrasta con los datos censales nacionales, que identifican a un 9,3\% de la población cubana como negra, un 26,6\% como mestiza y un $64,1 \%$ como blanca, según las categorías basadas en el color de la piel (cfr. Censo de Población y Viviendas de Cuba 2012, http://www.one.cu/informenacional2012. htm, consultado el 15 de septiembre del 2016).

Según las estadísticas citadas en algunas fuentes, el 25\% de los alavenses llevan Zulueta en uno de los apellidos; el 12\% lo llevan en los dos (Marrero 2005). construido de mampostería y teja. [...] Del exterior se entraba generalmente a un pequeño zaguán atravesando una amplia puerta [...] a la derecha las dos habitaciones del negro contramayoral y su familia, a la izquierda la habitación donde estaba el cepo" (129). 
[...] un maestro de azúcar, con apellido vasco y un alumno de un francés, que era químico para determinar los parámetros del azúcar. Él tenía unos cuartos preparados para esas personas y los atendían esclavas. Eran alrededor de tres blancos. Los negros vivían todos en el barracón. (Pedro Díaz del Castillo, entrevista, Central México, diciembre del 2014)

A partir de estos relatos y recorridos que localizan temporal y espacialmente el trauma y el terror de la esclavitud, pude entrever cómo la comunidad, según los testimonios recopilados, fue elaborando ambivalentes narrativas de rebeldía y de resistencia en cuanto a la "tradición” y el "orgullo" local, como veremos.

Los habitantes se dedican a diferentes actividades derivadas de la producción del azúcar y del trabajo agrícola y ganadero, además de servicios a la población, principalmente en educación y salud, de acuerdo con la eficiente planificación estatal en estas áreas. El Central México se caracteriza además por diferentes factores patrimoniales que, como indican estudios realizados localmente (Marrero 2005; Villegas et al. 2013a), lo destacan a nivel nacional: la torre campanario original e intacta, el barracón de los esclavizados y el fuerte militar, una represa construida en la época colonial para abastecer de agua al ingenio y un cementerio de esclavizados. Además, distingue al batey la vigencia de prácticas culturales afrocubanas que conforman el rico acervo cultural local y son consideradas parte fundamental del patrimonio cultural inmaterial: prácticas religiosas, artísticas, dancísticas y musicales, valorizadas localmente como herencia de los ancestros africanos que lo habitaron. En efecto, se encuentran allí algunas de las más antiguas casas templo de la isla pertenecientes a los sistemas religiosos de la regla de Ocha e Ifá y del palo monte, que conservan piezas y objetos de culto originarios de la época colonial, algunos traídos de África por los esclavizados, y los “asientos de santos” fundados en la época colonial que hoy continúan "activos" 20 . Estos últimos son lugares sagrados cuya existencia y significados son transmitidos por tradición oral y localizados en diferentes lugares del batey —barracón, árboles, represa, zanjas- en donde habitan las deidades yorubas, los orishas de la regla de Ocha e Ifá. Los espacios, los saberes y las prácticas culturales son significados y actualizados por los habitantes del batey -no solamente por los afrodescendientes o por los practicantes de estas religiones-, en cuanto elementos fundamentales de la identidad local y parte de la vida cotidiana de las personas ${ }^{21}$.

20 La importante difusión de las prácticas religiosas convierte al Central México en un significativo destino de turismo religioso nacional e internacional. campo en el 2014 y el 2015, con el apoyo y la participación de los hermanos Villegas Zulueta 


\section{Azúcar y látigo o la performatividad de la memoria}

Cuando llegué al Central Azucarero México la primera vez, en el 2012, lo hice de la mano de Anselmo Villegas Zulueta, biólogo e investigador de la historia de su comunidad y cofundador, junto a sus hermanos, del proyecto THNA. Nos encontrábamos allí con la delegación del Taller de Antropología Afroamericana de la Casa de África, institución habanera que promociona el patrimonio cultural afrocubano y que cada año programa visitas especializadas en diferentes localidades de la provincia de Matanzas ${ }^{22}$. En esa ocasión, los habitantes del batey organizaron una representación performática de escenas de la esclavitud y de la emancipación de los africanos esclavizados que vivieron allí. Frente a la torre campanario que abría el espacio del antiguo barracón, alrededor de veinte personas, entre jóvenes, adultos y niños, transformaron la calle en un escenario en donde se desarrolló el evento. Se sucedieron toques de tambores, bailes y cantos de las religiones afrocubanas, particularmente la regla de Ocha e Ifá y palo monte; escenas de la vida colonial que retrataban a los esclavizados en sus diferentes tareas - lavanderas, yerbateros, corteros de caña, etc.- y a los mayorales persiguiendo y azotando a los rebeldes o, en ocasiones, a mujeres, ancianos y enfermos representados por los actores. En escena estaban dispuestos diferentes objetos: grilletes de hierro originales, machetes, herramientas de trabajo de la zafra y del ingenio, fajos de caña de azúcar, entre otros. Estos objetos eran empleados para dar mayor eficacia y realismo a la representación. Los espectadores estábamos ubicados en semicírculo alrededor de la escena; los pobladores del batey que asistían al espectáculo participaban activamente acompañando los cantos, bailando, comentando e interviniendo de diversas formas, también con risas y exclamaciones de estupor, aprobación o rechazo, según lo que sucedía en cada escena. Es decir, durante toda la representación, que duró un poco más de media hora, los actores principales interactuaban con quienes intervenían desde el público, creando una situación de participación coral similar a la de otras representaciones populares que observé, especialmente las de carácter religioso.

y los pobladores del batey. Este fue realizado en el marco del taller de metodologías participativas de registro audiovisual y fotográfico organizado por Crespial en el 2015, con un proyecto documental que obtuvo una mención de honor por parte de esta entidad. El video se encuentra disponible en https://vimeo.com/200477449.

La Casa de África de la Oficina del Historiador de la Ciudad de La Habana reúne cada año a centenares de científicos convocados al Taller de Antropología Afroamericana que organiza la institución. 
El clima general era de fiesta, jocoso, solemne o irónico según los momentos, y los tiempos estaban marcados por los toques de tambor, los cantos y los silencios. El momento culminante y que introdujo el cierre de la performance fue la llegada a caballo de esclavos fugitivos que lograron vencer a los mayorales y liberarse de los grilletes, luego de una pelea cuerpo a cuerpo. Siguieron un gran aplauso y exclamaciones del público, mientras los músicos y bailarines retomaron los toques y las danzas que dieron el cierre al espectáculo.

Desde la perspectiva de las teorías de la performance y desde una visión procesual de los fenómenos sociales, las prácticas culturales son actuaciones que conforman dispositivos de acción y de narración que tradicionalizan elementos del pasado a partir de las disputas del presente, en los contextos sociohistóricos específicos (Bauman 1992; Turner 1986; Vich y Zabala 2004; Williams 2000). En la actuación analizada, podemos identificar tres temas centrales: a) las tareas de trabajo de los hombres y mujeres esclavizados en el antiguo ingenio, b) la violencia esclavista, c) la resistencia y rebeldía de los esclavizados que concluye en la liberación. En el primer tema aparecen diferentes elementos (la caña de azúcar, las herramientas), escenas de trabajo y tareas cotidianas; respecto del segundo tema tenemos una serie de elementos y de escenas de castigos y persecución de los mayorales; para el tercer tema están las armas empleadas por los fugitivos y las escenas finales de liberación. La música, de tambores y otros instrumentos percutidos en todas las escenas, es un elemento central de la representación. Los toques acompañaban los cantos y los movimientos de los actores: la intertextualidad, la oralidad y la corporalidad configuraban el metarrelato de la representación, perfectamente comprensible por los lugareños que asistían como espectadores-actores. Los diálogos eran escasos, limitándose muchas veces a palabras y frases pronunciadas por los mayorales, los gritos de liberación o las interacciones más o menos espontáneas entre los actores, y entre estos y el público. Cabe destacar que los intérpretes y la mayor parte de la audiencia eran habitantes del batey, exceptuando la delegación del Taller de Antropología de Casa de África y algunos vecinos de otros poblados. De manera significativa, todos los intérpretes eran negros y mulatos en las categorías locales, es decir, no hubo representación de personajes connotados como blancos, no aparecieron en la escena don Julián Zulueta ni otros personajes blancos del poder colonial. Era una performance pensada y realizada íntegramente por los descendientes de los esclavizados, un punto de vista sobre su propia historia o, por lo menos, sobre el acontecimiento histórico fundacional del batey.

Los elementos religiosos, la música y las danzas son los elementos metadiscursivos de la representación, que comentan y dan un sentido social compartido 
de lo que sucede en la escena. La performance es entonces un potente dispositivo narrativo que actualiza experiencias del pasado y las resignifica en el contexto actual. Los intérpretes traen a los antepasados esclavizados a la escena, en un sentido real más que metafórico; el espacio de la narración es el mismo que el espacio habitado actualmente: el ingenio, el barracón ${ }^{23}$. El tiempo del pasado esclavista se configura así como acontecimiento histórico acabado gracias a la lucha, pero sigue interpelando el tiempo presente de los descendientes que se posicionan como los seguidores de aquellas luchas. La performance no es solamente una representación que describe o enuncia una situación, es una acción que interviene en la construcción de la realidad, una forma concreta de conciencia y de visión del mundo.

Este recibimiento performático en el Central México puso en escena una serie de cuestiones que más tarde iba a poder profundizar durante mi estadía de campo. Me interesa aquí apuntar dos temas de análisis: por un lado, las múltiples funciones del relato representado, que podemos analizar a partir de sus elementos discursivos. Por otro lado, las implicaciones de este tipo de espectáculo en el marco de las políticas culturales oficiales. ¿Hasta qué punto es posible considerarla una práctica "culturalista" domesticada y desprovista de contenido político? Vemos en esta actuación performática múltiples funciones, y en algún punto contradictorias. En primer lugar, pone en escena un episodio significativo de la historia local, la violencia y el terror de la esclavitud, la emancipación y liberación de los esclavizados, según un relato homogéneo y lineal de condena a la esclavitud y de celebración de la libertad. A su vez, conecta esta experiencia con la identidad local, dejando fuera las violencias y los conflictos posesclavistas enfrentados por la comunidad. La elección del tema de la performance se torna ambivalente si lo pensamos en relación con la circunstancia por la cual se realizó y con el público. Es posible notar dos tipos de audiencias: una "experta” y local - los habitantes del batey_ y una "inexperta” y externa - los participantes foráneos- en ocasión de cuya visita se organizó el espectáculo. Estas diferentes audiencias contribuyen en la formación y en el control de significados de diversas maneras. Los habitantes del batey reconocen las habilidades de sus vecinos e intervienen en la realización de la performance: discursivamente, comentando, aprobando, y exclamando y acompañando la danza, el canto y el

Esta simultaneidad de temporalidades y de relación con los antepasados tiene semejanzas significativas con lo que acontece en otros espacios performáticos: el espiritismo y los rituales de las religiones afrocubanas, en donde la posesión por parte de espíritus, de deidades, los orishas en la regla de Ocha, o de los muertos, en el palo monte, son un elemento ceremonial central. El análisis de los aspectos religiosos excede el presente trabajo, pero los considero parte fundamental de la configuración sociocultural del batey. 
ritmo corporalmente. Por su lado, la audiencia externa, inexperta en el aspecto anterior, está conformada por "expertos" pero en otro sentido: los investigadores del taller de antropología y las autoridades presentes de patrimonio y cultura. Todos parecen concordar con el mensaje relevante del espectáculo: la resistencia cultural de los afrodescendientes y la liberación de la esclavitud fueron acontecimientos centrales en la historia local y nacional, que es preciso recordar y celebrar. Ahora bien, ¿qué sucede con la situación de los descendientes en las épocas posteriores? ¿Por qué no fue objeto de reflexión performada en esa instancia? Los diferentes significados se superponen, complejizando esta representación.

Figura 2. Escena de la representación de la esclavitud y liberación frente al barracón.

Central Azucarero México, enero del 2012

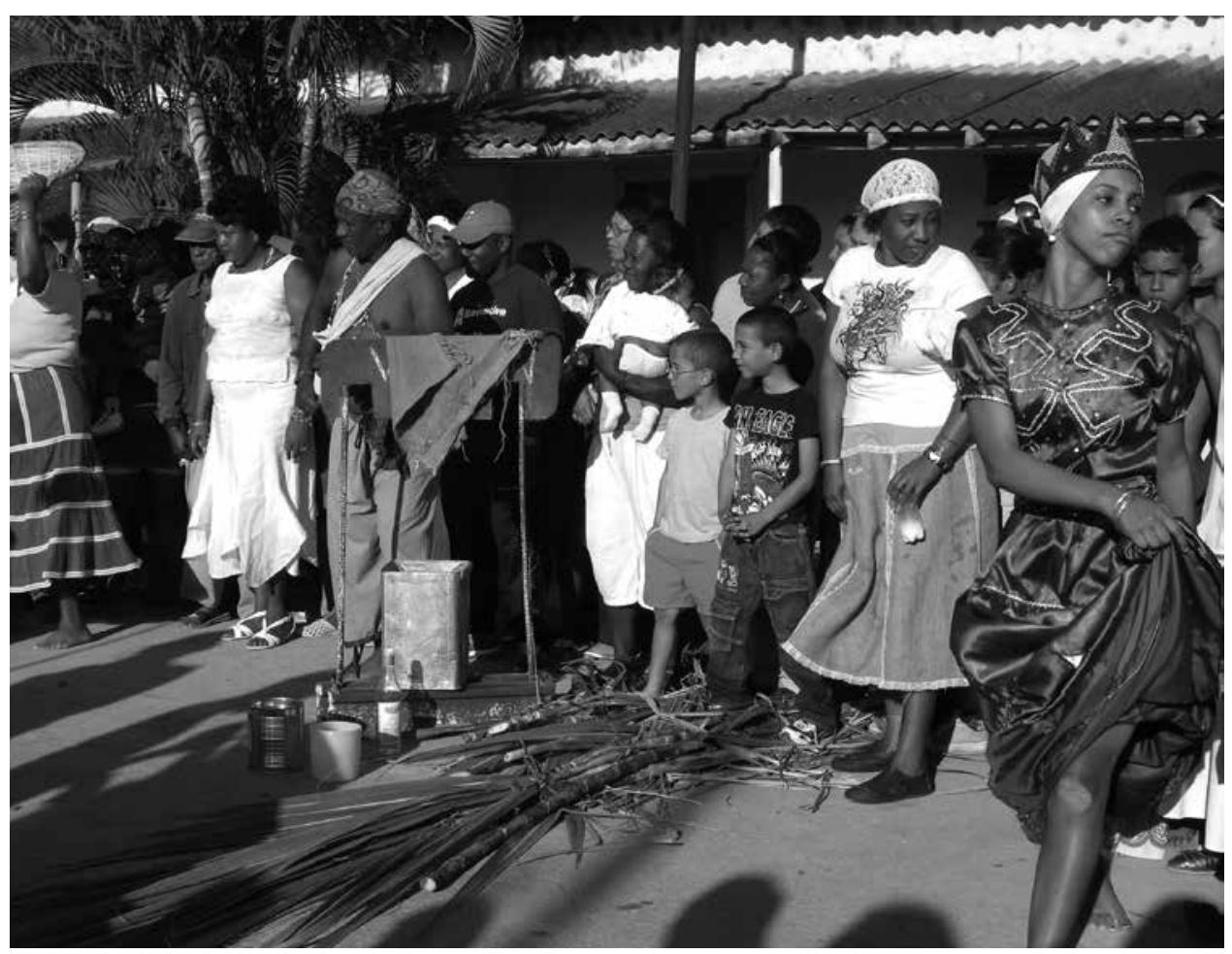

Fuente: elaboración propia. 


\section{"Tras las huellas de nuestros ancestros"}

Este es un ingenio que está lleno de gente

$y$ toda esta gente hace el ingenio.

Eneida Villegas Zulueta

(conversaciones, Central México, diciembre del 2014)

El proyecto comunitario “Tras las huellas de nuestros ancestros” (THNA) se constituyó a mediados de los años ochenta con el impulso de los hermanos Villegas Zulueta, con el objetivo de rescatar y reconstruir la historia local frente a la falta de investigaciones al respecto y a la situación de precariedad de los bienes comunes, tanto materiales - las ruinas del ingenio, el barracón, etc.- como inmateriales - las expresiones artísticas y religiosas afrocubanas locales-. Anselmo y Eneida, junto con otros miembros de la familia y de la comunidad, realizan desde entonces una minuciosa investigación sobre diferentes aspectos de la vida durante la esclavitud a partir de historias orales, leyendas y testimonios, para reconstruir las huellas materiales e inmateriales del central. Gracias al constante trabajo de difusión de los hermanos Villegas Zulueta, el proyecto ha obtenido un alto grado de reconocimiento a nivel nacional, a partir de la participación de algunos de sus miembros en diferentes espacios, como la Unión de Escritores y Artistas de Cuba (Uneac) y el Comité Cubano del proyecto Unesco de La Ruta del Esclavo, del cual es parte ${ }^{24}$. El proyecto coordinado por Eneida y Anselmo integra a diferentes familias de la comunidad, incluyendo a los "portadores de tradiciones afrocubanas”, según la categoría local: músicos, bailarines, practicantes de las religiones afrocubanas con sus casas templo, artistas plásticos, cocineros, educadores y artesanos.

Anselmo hoy un reconocido biólogo y docente del Departamento de Morfofisiología en la Facultad de Ciencias Agropecuarias de la Universidad de Camagüey, ciudad donde habita, luego de realizar un doctorado en ciencias biológicas en la antigua U. R. S. S. También es miembro del comité cubano de La Ruta del Esclavo y de la Uneac. Eneida, su hermana, es maestra jubilada, licenciada en educación primaria, promotora cultural y directora de la sala museo Ma' Carlota de la comunidad. Es una figura muy destacada y querida en el batey. Eneida y Anselmo me hablan con mucho orgullo y satisfacción del trabajo que llevan

\footnotetext{
24 Un listado con las actividades realizadas por el proyecto "Tras las huellas de nuestros ancestros" en el año 2013 se puede ver en el informe del Comité Nacional de Cuba, en www. lacult.org/docc/Cte_Cub_R_E_Info_2013.pdf (consultado en agosto del 2015).
} 
adelante con el proyecto. Me cuentan que nació oficialmente en enero de 1983, para el día del cumpleaños de Eneida y en continuidad con el mandato familiar:

[...] el proyecto surge con mis abuelos y mis padres que siempre tuvieron una vocación de historia, de conocer la historia del lugar, de las familias, del sufrimiento... Y resultó que a los siete hijos nos dio por continuar este trabajo desarrollado por ellos. (Anselmo Villegas Zulueta, entrevista, La Habana, diciembre del 2014)

Eneida comenzó investigando sobre los esclavizados, qué nombres tenían y cómo vivían (Eneida, entrevista, Central México, diciembre del 2015). Gracias a su buena reputación y a la confianza de la que goza en el batey, de a poco fue recopilando anécdotas, relatos, historias de las familias y también objetos que la gente le iba entregando. Con estos materiales conformó un archivo de la comunidad en su propia vivienda y luego en una sala al lado del campanario, en la entrada del barracón, cedida para tal fin. En el 2011, los hermanos Villegas Zulueta presentaron un proyecto titulado "Repercusiones de un museo en una comunidad” en una convocatoria de Crespial y salieron ganadores: con ese dinero se construyó la primera sala museo del central que lleva el nombre de la tatarabuela de Eneida y Anselmo, Ma' Carlota, una africana esclavizada muy presente en la memoria de los comuneros (Villegas et al. 2013b).

El proyecto THNA tiene tres ejes fundamentales: la investigación de la historia local a partir de la memoria oral y la documentación disponible - fotografías, prensa local, documentos de la industria azucarera, archivos coloniales y poscoloniales-; el trabajo social comunitario, focalizado en actividades socioculturales y educativas principalmente con los jóvenes; la difusión y socialización de los resultados ${ }^{25}$. Entre los principales logros comunitarios del proyecto, Eneida y Anselmo destacan la reactivación en los años noventa de la fiesta del Día del Alavense Ausente, que se desarrolla cada año en agosto, fecha de fundación del ingenio y creación de la sala museo Ma' Carlota ${ }^{26}$. El proyecto aborda "los problemas de la comunidad en estos tiempos de globalización neoliberal y las consecuencias que ha dejado el hecho de haber sido esclavos, los problemas de racialidad y los problemas que subsisten en escala universal” (Anselmo,

Vale la pena mencionar que los resultados de las investigaciones son presentados por sus miembros cada año en uno o dos eventos internacionales de estudios afrocubanos, principalmente el Taller de Antropología Afroamericana de la Casa de África de La Habana y el Festival del Caribe en Santiago de Cuba. Fue en uno de estos eventos que conocí a Anselmo, en el año 2008.

Un listado de las actividades realizadas por el proyecto THNA en el año 2013 se muestra en el informe del Comité Nacional de Cuba de La Ruta del Esclavo, Unesco, disponible en www. lacult.org/docc/Cte_Cub_R_E_Info_2013.pdf. 
entrevista, La Habana, diciembre del 2014). El objetivo principal es concientizar a los pobladores sobre el gran valor patrimonial que conserva el batey, con el fin de protegerlo y generar oportunidades para que los jóvenes puedan dedicarse a su preservación, incluyendo proyectos de turismo cultural. En palabras de otro miembro del proyecto THNA, un joven artista plástico que interpretó al esclavizado rebelde en la performance que vimos:

[...] representar la esclavitud es una forma de echar a ver mis raíces, cosas que a veces la gente discrimina un poco y no es realmente lo que la gente piensa, porque a veces dicen "esclavo, santo... es algo que se queda obsoleto", pero no, es identidad, es lo que nosotros vivimos y es lo que trato de reflejar en mi obra. (Yohandy Zuaznabar Montalvo, entrevista, Central México, diciembre del 2014)

Como he podido observar, los habitantes del batey apelan de diferentes maneras al valor patrimonial de los espacios que habitan y de sus saberes, principalmente en función de sus expectativas y necesidades. ¿Cuáles son los diferentes sentidos de patrimonio que otorgan los pobladores del Central México? Anselmo se queja notablemente del estado de abandono en que se encuentran algunos de los bienes - principalmente los asientos de santos ubicados al aire libre-, producto del desinterés de los propios comuneros que "no saben de qué se trata" o "no les importa”. Por su parte, la coordinadora del área de investigación de la casa de cultura local también habla de la precariedad de las estructuras originales del batey y afirma que, frente a las carencias económicas estatales que impiden una financiación suficiente, debe aprovecharse el proyecto de La Ruta del Esclavo para refaccionar los bienes inmuebles del central según las propuestas de los pobladores, es decir, no por imposiciones foráneas. Por otro lado, considera fundamental rescatar las tradiciones locales como la rumba, porque se está perdiendo su práctica: "nosotros somos rumberos de nacimiento [...] pero los jóvenes no están para eso... y me da tristeza” (Clara Diviñó Zulueta, entrevista, Central México, diciembre del 2014). Efectivamente, un tema emergente son las tensiones entre las diferentes generaciones. Los jóvenes en muchos casos prefieren bailar reguetón e ir a buscar trabajo, fortuna y diversión en el polo turístico de Varadero. No ven el patrimonio como un potencial factor de desarrollo local. ¿“Qué tengo que hacer yo acá...? No tengo nada que hacer”, se pregunta Rosy, una joven de veinte años ${ }^{27}$.

27 Otros actores sociales importantes que intervienen en la significación del patrimonio local son los practicantes de las religiones afrocubanas, muy difundidas en el batey, cuyo análisis será abordado en otra ocasión. 


\section{La sala museo Ma' Carlota}

Ubicada al lado de la torre campanario, la sala museo Ma' Carlota es la primera y única de la comunidad. Se trata de dos pequeñas salas contiguas y un pequeño patio trasero. Ocupa el lugar en donde se encontraban la casa de los mayorales y el cuarto de torturas del barracón por donde los africanos tenían que transitar para ir a trabajar y así ver diariamente todos los aparatos del terror. Hacia el fondo de lo que hoy es la sala museo, se ubicaban los cuartos para la reproducción y el parto, una enfermería y la cocina (Anselmo, entrevista, Central México, diciembre del 2014). Un lugar que tiene "historias muy tristes" y los habitantes del batey lo consideran sagrado por eso (Anselmo, entrevista, Central México, diciembre del 2014) (figura 3). Lleva el nombre de la última africana esclavizada de don Julián Zulueta, que fue ama de pecho de su hijo Julián y es la tatarabuela de Anselmo y Eneida ${ }^{28}$. Se inauguró el 21 de agosto del 2013, el Día del Alavense Ausente, una fecha muy significativa para la comunidad, que corresponde a la fundación del ingenio, y en esa ocasión se realiza una gran celebración para recordar a los antepasados y reforzar los vínculos de la comunidad. Desde un punto de vista administrativo, la sala museo Ma' Carlota no es independiente, es una extensión del Museo Municipal de Colón, el municipio cabecera. Eneida ha sido nombrada directora y a su lado trabaja un especialista en historia que vive en un poblado cercano.

En la sala se cuenta la historia del central desde la época de la esclavitud hasta la actualidad, a través de un relato fotográfico, textual y de piezas originales, ideado y gestionado por el proyecto THNA (Villegas et al. 2013b). Se exhiben más de treinta objetos colocados en vitrinas o sobre soportes de madera en las dos salas. Se exponen fotografías e imágenes del central en diferentes épocas, fotografías con los peinados que empleaban las esclavizadas y que hoy están en uso; un cartel con los "nombres de los esclavizados más famosos” y otro con los "refranes de los esclavos”, muchos de ellos aún vigentes. Los estudiantes de la

Entre las tareas asignadas a las esclavas, una de las principales fue la de nodriza o ama de pecho de los hijos de sus amos blancos. Para realizar esta función, las madres negras debían postergar o delegar el cuidado de sus propios hijos, como Ma' Carlota. Ella fue obligada a abandonar a su hijo para dedicarse al cuidado del hijo de "su amo", conocido como Juliancito, siguiéndolo a La Habana y luego a España, y regresó al Ingenio Álava después de muchos años. Al ver que su propio hijo había muerto, Carlota "se volvió loca", como se cuenta localmente. Juliancito le regaló una cama de hierro "en agradecimiento por sus servicios" y le cedió un lote en donde Carlota construyó una casa para su familia, que hoy pertenece a sus descendientes, entre ellos Eneida y Anselmo. La cama de hierro se exhibe en la sala museo Ma' Carlota (conversaciones con Eneida y Anselmo Villegas Zulueta, Central México, diciembre del 2014 / enero del 2015). 
escuela primaria del batey se familiarizan con todo este rico acervo gracias al trabajo educativo que el museo promueve.

Figura 3. Vista de la Sala Museo Ma' Carlota, diciembre del 2014

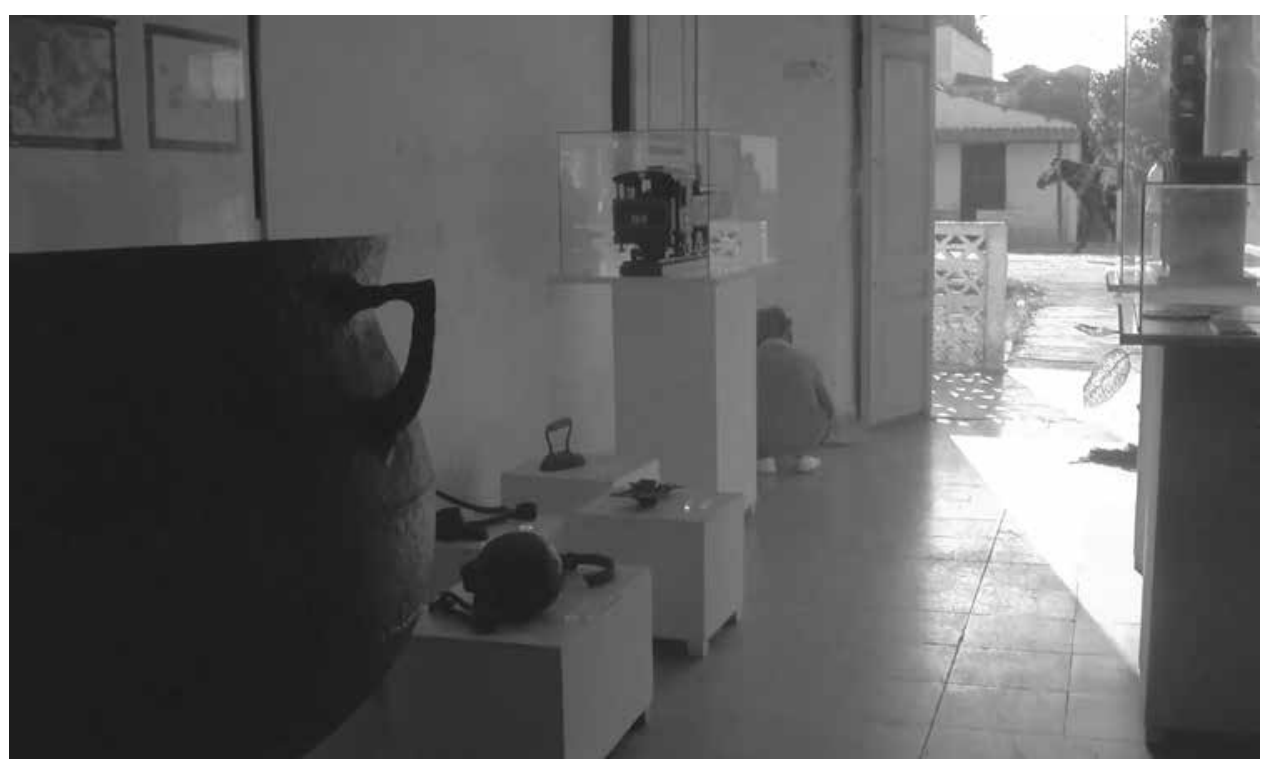

Fuente: elaboración propia.

Los objetos que se exhiben son principalmente los que pertenecieron a los antepasados de las diferentes familias del batey. Entre ellos ocupa un lugar de relieve la cama de hierro de Ma' Carlota y un pequeño altar en el suelo al costado de la cama, compuesto por objetos de culto de la regla de Ocha. En la sala-pasillo, entre plantas verdes y bajo la suave luz natural, están colocados calderos, morteros, cadenas y grilletes que pertenecieron a diferentes esclavizados de los cuales se indican los nombres; también se muestran objetos rescatados de la casa de Julián de Zulueta y herramientas del central azucarero de la época posesclavista. En la sala del fondo, donde se ubica el escritorio de Eneida y un archivo de documentos guardados en un armario, hay vitrinas que exponen armas de las revoluciones independentistas que se emplearon en Álava y otros objetos apoyados o colgados en las paredes. En la exposición de las salas hay también objetos de las religiones afrocubanas — cuencos, muñecos, vasijas, imágenes-, pero no están simplemente “expuestos”, no son objetos inertes: su presencia cumple funciones de protección y resguardo asociadas con deidades específicas. Es el caso de Elegguá, orisha mayor del panteón yoruba y santo patrono del Central México, cuya representación —un caracol y otros atributos — se encuentra en la entrada 
del museo, al costado de la puerta. "Elegguá protege al museo y a los que nos visitan, por eso si quieres pídele y déjale una ofrenda”. Lo que allí se deposita, cuenta Eneida, es un aporte para mantener la sala museo, “con el permiso de Elegguá” (Eneida, entrevista, Central México, diciembre del 2014) ${ }^{29}$. Este uso instrumental "permitido" es parte de la misma práctica religiosa cuya función es también la de "resolver” problemas cotidianos de los fieles (Menéndez 2001). Es de destacar que estas estrategias económicas se refieren a los usos instrumentales de la religión y cabe preguntarnos entonces qué conflictividades conllevan, considerando además que Eneida no es practicante, según lo que ella misma declara.

La problemática económica es un tema que ocupa un lugar destacado en las preocupaciones de los miembros del proyecto. Los hermanos enfatizan los logros y los impactos positivos alcanzados gracias al apoyo de la comunidad, pero también demuestran inquietud en cuanto a la posibilidad de seguir manteniendo el proyecto, principalmente por falta de los apoyos económicos necesarios y, no lo esconden, por "ciertos celitos" que hay en la comunidad. Frente a esto, Eneida y Anselmo mantienen dos posturas para legitimar y dar continuidad al proyecto. Por un lado, destacan que es un trabajo que hacen "de gratis” y "de corazón”, por lo cual las envidias y los chismes de otros pobladores - que los acusan de beneficiarse personalmente, no tanto en términos económicos como por el prestigio y poder - no tienen razón de ser. Dar continuidad al proyecto THNA y gestionar el museo Ma’ Carlota constituye una obligación con la comunidad y, de manera particular, con las nuevas generaciones: “ya que uno puso el corazón, ¡no puede sacar el cuerpo!” (Eneida, entrevista, Central México, diciembre del 2014).

Por otro lado, consideran fundamentales las alianzas estratégicas con instituciones del Estado y organismos internacionales para alcanzar los objetivos que se proponen, también en cuanto plataformas de visibilidad. Esto da cuenta de la importancia del premio Crespial recibido para la creación de la sala museo; la inclusión del proyecto THNA en el comité cubano de La Ruta del Esclavo Unesco, y el reconocimiento del Ingenio Álava a nivel provincial y nacional como sitio significativo de la presencia africana y su postulación para la declaración de patrimonio nacional. En este marco, Eneida comenta las expectativas que se generan con las visitas de instituciones y personalidades destacadas de Cuba,

29 Entre los artefactos de uso religioso de la época esclavista que aún se conservan en el batey se encuentra una estatuilla de madera que, según la tradición oral, ha sido traída desde África por uno de los más famosos esclavos, Ta Jorge. Este africano, proveniente de lo que hoy es Nigeria, fundó la casa templo de Elegguá que hoy sigue funcionando como tal. Todos los años, el 24 de octubre se celebra la fiesta de Elegguá, el santo patrono del central, a la cual asisten también desde otros poblados cercanos, y hasta visitantes extranjeros iniciados en la regla de Ocha. 
principalmente con ocasión de la fiesta del Alavense Ausente, cuando acuden los alavenses que residen afuera, como el caso de Anselmo, delegaciones de religiosos, artistas e investigadores que vienen de La Habana y miembros de organismos estatales de cultura. Por ejemplo, visitaron el batey el presidente de la Asociación Yoruba de La Habana, autoridades de organismos estatales de cultura y patrimonio, diplomáticos africanos y los investigadores del Taller Internacional de Antropología de Casa de África en el 2012. De estas y otras visitas “ilustres” da testimonio el libro de firmas custodiado en el museo que, de alguna manera, funciona como un metaarchivo de este: allí se conservan las dedicatorias, las fechas y las firmas de todas las personas que pasaron por ahí y que son motivo de orgullo para los pobladores ${ }^{30}$.

\section{Notas finales. Usos locales del patrimonio}

Las estrategias de escritura de una historia propia sistematizadas en la experiencia de la sala museo Ma' Carlota posicionan a la comunidad y al proyecto THNA como sujetos activos en la arena de negociaciones de significados y de gestión del patrimonio, la tradición y la memoria local. Hay una idea compartida entre los habitantes de que la precariedad en la que se encuentra el batey se podría sanar promoviendo circuitos de turismo cultural o de memoria y así garantizar una entrada económica para restaurar los edificios históricos, además de generar ingresos para las familias. Cabe mencionar que uno de los objetivos estratégicos de La Ruta del Esclavo, en articulación con la Dirección Provincial de Patrimonio de Matanzas, es justamente desarrollar circuitos de turismo cultural en los centrales azucareros. Matanzas se ubica en la principal ruta turística de Cuba que une a La Habana con el complejo turístico de Varadero, en la misma provincia. Dicho corredor está escasamente conectado con los sitios de memoria de los diferentes municipios: toda la extensa zona de ingenios azucareros y la misma ciudad de Matanzas quedan al margen de esta oportunidad, lo que compromete el desarrollo económico local. La principal razón que exponen los miembros del comité nacional de La Ruta del Esclavo y los del proyecto THNA entrevistados es, paradójicamente, la falta de interés por parte del Ministerio de

30 Un caso muy significativo y a la vez ambivalente es la visita que realizaron en varias ocasiones los descendientes de Julián de Zulueta, que hoy viven en España. En el 2008 estuvo el bisnieto de Juliancito, el hijo de don Julián criado por Ma' Carlota, que "vino aquí a ver la cama" (Eneida, entrevista Central México, diciembre del 2014). 
Turismo en realizar estos circuitos. Según ellos, persiste la idea de que hablar de esclavitud es hablar de "cosas de negros" y no es un tema relevante para las políticas institucionales. Esta falta de interés desvela las tensiones del Estado cubano y de la sociedad frente a una temática compleja como lo es la cuestión racial, y que el patrimonio como recurso simbólico y económico bien pone en evidencia. Frente a la ausencia de financiación estatal, los miembros del proyecto THNA movilizan el patrimonio local como recurso simbólico y económico, atrayendo visitantes y proyectándose a nivel internacional, principalmente a través de La Ruta del Esclavo y de Crespial, como vimos. Sin embargo, ello no sucede de manera uniforme y consensuada entre los pobladores y los miembros del proyecto. El patrimonio se convierte de este modo en una herramienta de reivindicación antirracista, porque pone al descubierto y combate las tramas silenciosas de las tensiones raciales en el marco de un sistema marxista-socialista que apela a la igualdad, pero que normaliza inequidades estructurales heredadas del sistema colonial y capitalista. Entiendo entonces que la apropiación y gestión del patrimonio común se constituye en una fuente de resistencia y reivindicación cultural y política de la población negra del central.

La narrativa local sobre la historia comunitaria reivindica una tradición de rebeldía, emancipación y resistencia a lo largo de la historia del ingenio, proponiendo diferentes lecturas, apropiaciones y usos del tiempo y del espacio, de objetos y de símbolos culturales. En efecto, tal como sostiene Hill (1992), las narrativas sobre el pasado refieren tanto a las condiciones de existencia de los antepasados, como a las relaciones sociales actuales de los enunciadores, en determinados contextos de construcción de hegemonía. En primer lugar, encontramos en los discursos y acciones del proyecto THNA la reivindicación de derechos específicos por su condición de negros y negras y la lucha por la autorrepresentación (Arantes 1997; Crespo, Losada y Martín 2007; Hall 2010). En este sentido, el patrimonio se configura como un "campo de alta tensión” (Aravena 2006), en cuanto a la atribución del valor patrimonial referido a un bien o a un conjunto de bienes, y produce instancias de discusión y negociación que trascienden lo simbólico-cultural, y se extienden también a demandas políticas y económicas (Cruces 1998; Rotman 2001). Los significados y los usos estratégicos del patrimonio cultural movilizados por los habitantes del batey, especialmente por el grupo THNA, se ubican en el marco de las demandas de reconocimiento y de lucha antirracista de las comunidades afrodescendientes a escala nacional, ya que "nuestra historia y nuestra manera de contarla, cuentan".

Alrededor de la historia del central, de la elaboración del azúcar y de la vida cotidiana de los habitantes del batey, se entrelazan profundas e intricadas vivencias subjetivas que van conformando memorias colectivas hechas de 
testimonios, recuerdos tangibles, espacios físicos y simbólicos de la presencia negra. Todos estos elementos conforman maneras de transmisión de la historia local, narrativas contestatarias, rebeldes y trascendentes sobre sí mismos.

Podemos pensar que los usos sociales de los artefactos, textos y símbolos culturales son modos de gestionar y producir significados culturales, pero también son formas subalternas de producción de historia, retomando la expresión acuñada por el africanista David W. Cohen en contextos poscoloniales (1994). La memoria se presenta como un territorio complejo en donde caben el trauma de la esclavitud y la herida colonial, parafraseando a Gilroy (2003) y a Mignolo (2007) respectivamente. Pero la memoria es también el espacio-tiempo de la rebelión constante, de la sanación y de la fiesta. El doble nombre del central, Álava y México, empleados casi de forma simultánea, pero con diferentes connotaciones histórico-políticas, habla también de las ambivalencias que recorren la experiencia colonial y contemporánea de los afrodescendientes.

La gestión del patrimonio local como bien común pone en evidencia que la "cultura", la "memoria" o el "patrimonio" son campos de disputas y posicionamientos de los sujetos en el contexto del poder colonial/moderno que se perpetúa sutilmente en el sistema socialista. Se trata de memorias encarnadas a través de los testimonios y de los objetos que "hacen recordar", y con ello se construye otra historia no contada en ningún libro oficial, cuyo valor principal es la reivindicación de las experiencias vividas: las de los esclavizados y sus descendientes. La sala museo Ma' Carlota conforma un archivo de memoria viva, material e inmaterial a la vez, realizado a partir de lo que las personas consideran relevante conservar y mostrar, un patrimonio local que va formando capas de memorias familiares, comunitarias y nacionales. Los modos de transmisión de estas memorias configuran así un concepto polisémico y polémico de patrimonio, más allá de los criterios y determinaciones impuestos por los organismos transnacionales o por diferentes instituciones nacionales.

En el batey se da una suerte de fagocitación ${ }^{31}$ de la experiencia colonial y poscolonial por parte de los habitantes, a partir de una incorporación de determinados elementos y prácticas. La materialidad es el sustento de las reivindicaciones: conservar los bienes inmuebles es importante porque "ahí viven los

31 Me refiero a la idea-experiencia de fagocitación sugerida por Rodolfo Kush (1999, 29), una vivencia de los pueblos americanos histórica antes que filosófica, una interacción dramática y dialéctica entre los opuestos que deriva en una sabiduría encarnada y profundamente política. El dibujo "Álava” que aparece al final del artículo es una buena representación de esta idea: la culebra o majá —animal del imaginario popular del batey y protagonista de leyendas locales- y el caracol —asociado con Elegguá, santo protector del batey- come y digiere el central azucarero, así como los africanos y sus descendientes fagocitaron la experiencia colonial y poscolonial. 
antepasados". En otras palabras, la materialidad de la memoria también da cuenta de la experiencia de los abuelos, de los antepasados, que se convierten en orientaciones para los actuales miembros de la comunidad. Esta idea-práctica supera la división material/inmaterial de las concepciones clásicas del patrimonio, según las definiciones derivadas de organismos internacionales, que recortan y reifican experiencias y memorias de grupos subalternos o reproducen saberes globales académicos (Carozzi 2003; Guanche 2004; Millán 2004). En cuanto “están ahí”, la materialidad de los objetos y sitios y los saberes y memorias sedimentadas sobre esos espacios adquieren un valor "patrimonializable" fundamental: desde ahí es posible reclamar reconocimientos, por ejemplo, a través de La Ruta del Esclavo de Unesco o Crespial, adaptándose a los requisitos que estas agencias imponen.

Debemos preguntarnos si la patrimonialización oficial -o la falta de patrimonialización - de sitios de memoria afroamericana - en nuestro caso afrocubana - responde a una objetivación de "otros culturales” y de "experiencias históricas impensables”, como diría Trouillot (1995); es decir, los negros/ afrodescendientes como sujetos de derecho y actores de historia y la esclavitud como proceso en el centro de la modernidad (Gilroy 2003; Trouillot 1995). Estas reflexiones abren interesantes pistas para articular los estudios en torno a la presencia africana en el Caribe y la opción decolonial en tanto enfoque crítico contemporáneo en las ciencias sociales (Castro-Gómez y Grosfoguel 2007; Hall 2010; Lao-Montes 2007; Mignolo 2010; Restrepo 2012) ${ }^{32}$.

Charles Hale advierte que es necesario plantearse una pregunta que por lo general no está siendo suficientemente considerada por la opción decolonial: cómo dar cuenta del terror racial que está en el centro de las experiencias de las comunidades negras en las Américas y cómo considerar la estrategia antirracista de la experiencia histórica y política de los afrodescendientes como pensamiento y práctica antisistémica colonial/moderna ${ }^{33}$. Las experiencias de las comunidades afrodiaspóricas

32 Es importante ver este cuerpo de literatura decolonial en el marco de una sociedad con un proyecto marxista-socialista y anticolonialista. Por lo que pude revisar, las teorías decoloniales dialogan muy poco con la producción intelectual cubana y viceversa, exceptuando interesantes apropiaciones de las propuestas de Fernando Ortiz como epistemología del sur (Mignolo 2010).

33 Hale (2014) ubica una importante carencia en las propuestas de las teorías decoloniales que se enfocan en la búsqueda de epistemologías otras excluidas de la modernidad, generalmente las cosmopolíticas indígenas. Apelando a la corriente teórica del afropesimismo, que describe la experiencia negra en general como una condición de muerte social, Hale plantea la ausencia de la crítica racial en las teorías decoloniales: la lucha antirracista pasaría a un segundo plano respecto de la búsqueda de ontologías alternativas, mientras que la lucha antirracista es central en cuanto lo es para los movimientos negros. Es decir, habría que considerar la dimensión decolonial de la experiencia política negra, intrínsecamente antirracista y translocal. 
o afrolatinas abren un territorio inexplorado que revela historias invisibles de América Latina y el Caribe, develando limitaciones conceptuales-analíticas de las ciencias sociales que tratan de abordarlas (Lao-Montes 2007; J. García 2005, 2015). En este sentido y sobre la base de los elementos que hemos analizado en este artículo, considero que la afrodescendencia —o la experiencia histórica encarnada de raza, parafraseando a Segato (2007)—, aporta reflexiones urgentes sobre racialidad y racismo en los estudios socioculturales.

Ahora bien, las performances culturales, la sala museo Ma' Carlota y la fiesta del Alavense Ausente, representan, en palabras de Gilroy (2003), contraculturas de la modernidad que ponen en marcha otras modalidades de interacción social más allá de las hegemonías internas —el Estado socialista cubano-y las hegemonías globales del capital —el multiculturalismo neoliberal-, porque se basan en formas colectivas de gestionar y entender los bienes comunes.

Figura 4. Vista del central azucarero en funcionamiento, chimeneas y enfriadero, enero del 2015

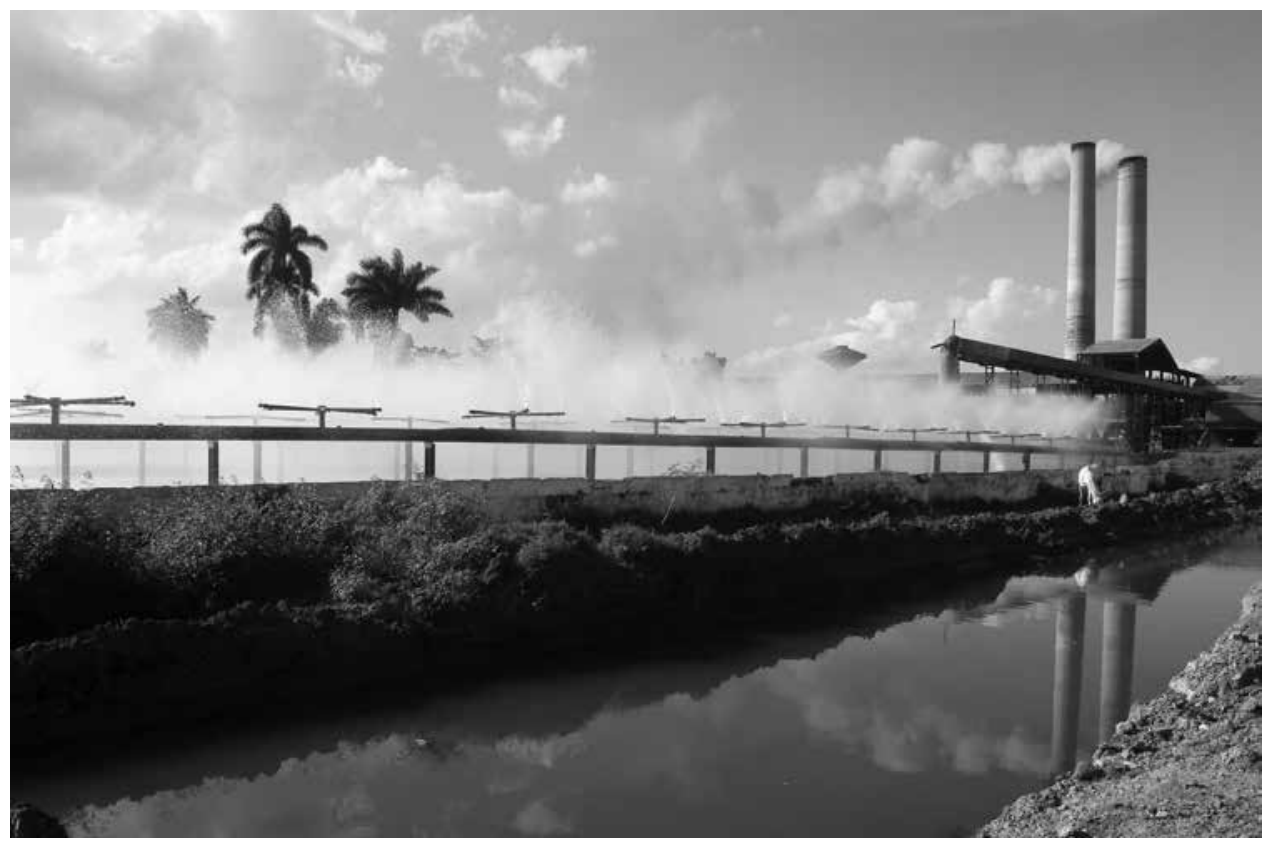

Fuente: elaboración propia. 
Figura 5. "Álava", dibujo en lápiz de Y. Zuaznabar. Copia de original

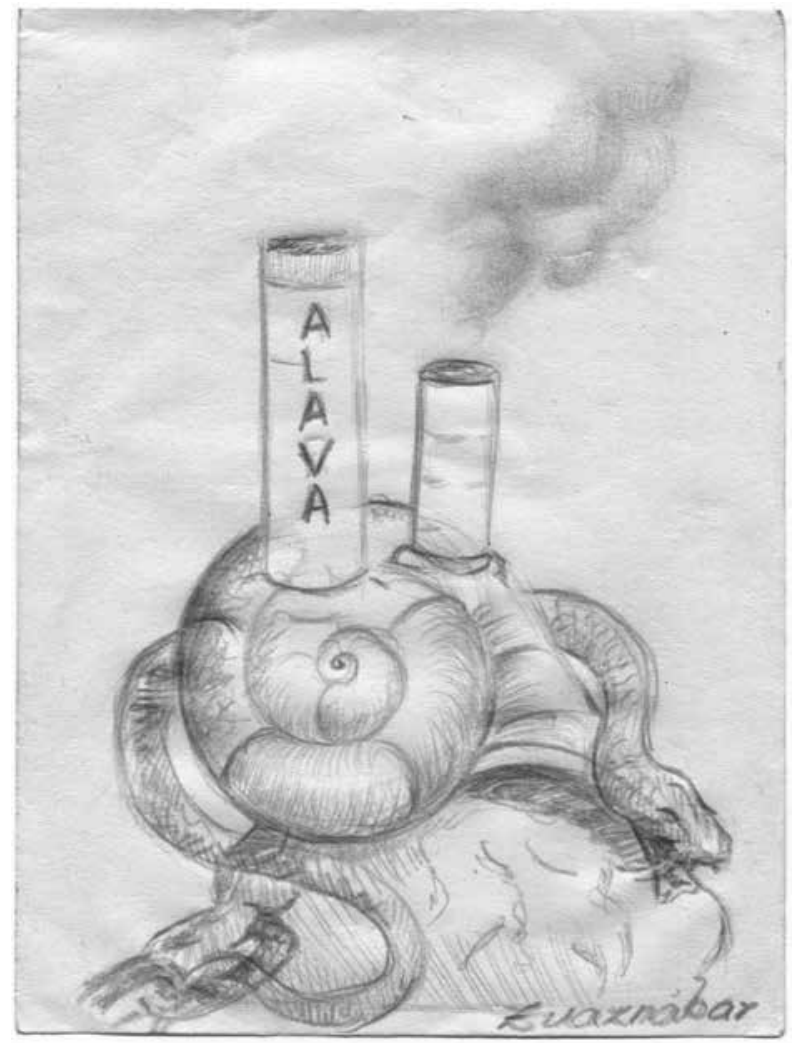

Fuente: cortesía del autor.

\section{Referencias}

Annecchiarico, Milena. 2015. "Fiesta, memoria y performance en el espacio público. Políticas culturales y reconfiguraciones afro en La Habana y en Buenos Aires”. En La política cultural en debate. Diversidad, performance y patrimonio cultural, compilado por Carolina Crespo, Hernán Morel y Margarita Ondelj, 51-89. Buenos Aires: Ciccus.

-. 2016. "Senderos de la diáspora africana en Argentina y en Cuba. Prácticas y políticas culturales en contexto”. Tesis de doctorado, Facultad de Filosofía y Letras, Universidad de Buenos Aires.

-. 2017. "La africanía y la cuestión racial en los estudios afrocubanos”. Tabula Rasa 27 : 249271. https://doi.org/10.25058/20112742.451.

—. En prensa. "Más allá de la africanía: nuevos discursos de 'lo afro' en Cuba contemporánea”. Cuban Studies 48. 
Arantes, Antonio. 1997. "Patrimonio cultural y nación”. En Trabalho, cultura e cidadania: um balanco da historia social brasileira, compilado por Ángela. M. Carneiro Araújo, 275-289. São Paulo: Scritta.

Aravena Núñez, Pablo. 2006. "Patrimonio, memoria e historia: la gestión del pasado en el mundo contemporáneo”. Revista Sepiensa , 7 de mayo. Consultado el 20 de octubre del 2016. www.sepiensa.net/edicion/index.php?option=content\&task=view\&id=649\&Itemid=40.

Barnet, Miguel. 1998. La fuente viva. La Habana: Letras Cubanas.

Bauman, Richard. 1992. "Performance”. En Folklore, Cultural Performances and Popular Entertainments. A Communications-Centered Handbook, editado por Richard Bauman, 41-49. Nueva York, Oxford: Oxford University Press.

Carbonell, Walterio. (1960) 2006. Cómo surgió la cultura nacional. La Habana: Ediciones Bachiller.

Carozzi, María Julia. 2003. "El reconocimiento de las formas populares y locales de la memoria en las políticas del patrimonio cultural”. En El espacio cultural de los mitos, ritos, leyendas, celebraciones y devociones, 501-512. Temas de Patrimonio 7. Buenos Aires: Comisión para la Preservación del Patrimonio Histórico Cultural de la Ciudad de Buenos Aires.

Castro-Gómez, Santiago y Ramón Grosfoguel, comps. 2007. El giro decolonial. Reflexiones para una diversidad epistémica y más allá del capitalismo global. Bogotá: Siglo del Hombre.

Censo de Población y Viviendas de Cuba. 2012. Consultado el 15 de noviembre del 2016. http://www.one.cu/informenacional2012.htm.

Cohen, David W. 1994. The Combing of History. Chicago: University of Chicago Press.

Colectivo de autores. 2011. Las relaciones raciales en Cuba. Estudios contemporáneos. La Habana: Fundación Fernando Ortiz.

Crespo, Carolina, Flora Losada y Alicia Martín, comps. 2007. Patrimonio, políticas culturales y participación ciudadana. Buenos Aires: Antropofagia.

Cruces, Francisco. 1998. "Problemas en torno a la restitución del patrimonio. Una visión desde la antropología”. Alteridades 8 (16): 75-84.

Escobar, Arturo. 2005. Más allá del Tercer Mundo. Globalización y diferencia. Bogotá: ICANH.

Fernández, Alejandro. 2012. "La polémica del color: las ciencias sociales en el debate racial”. Revista de la Universidad de La Habana 273: 4-7.

Fernández, Mirta. 2005. Oralidad y africanía en Cuba. La Habana: Editorial de Ciencias Sociales.

Ferrer, Ada. 2011. Cuba insurgente. Raza, nación y revolución. 1868-1898. La Habana: Editorial de Ciencias Sociales.

Franco, José Luciano. (1978) 2011. La gesta heroica del Triunvirato. La Habana: Editorial de Ciencias Sociales.

-.1980. Comercio clandestino de esclavos. La Habana: Editorial de Ciencias Sociales.

García Canclini, Néstor, ed. 1987. Políticas culturales en América Latina. Ciudad de México: Grijalbo. 
García Valdés, Jesús. 2005. "Encuentros y desencuentros de los 'saberes' en torno a la africanía 'latinoamericana”. En Cultura, política y sociedad. Perspectivas latinoamericanas, editado por Daniel Mato, 359-377. Buenos Aires: Clacso.

—. 2015. "Afrodescendientes: identidad y cultura de resistencia”. América Latina en Movimiento. Agencia Latinoamericana de Información. https://www.alainet.org/es/articulo/168972.

Gilroy, Paul. 2003. The Black Atlantic. L'identità nera tra modernità e doppia coscienza. Roma: Meltemi.

Grimson, Alejandro. 2011. Los límites de la cultura. Crítica de las teorías de la identidad. Buenos Aires: Siglo XXI.

Guanche, Jesús. 2004. “¿l patrimonio de la cultura popular tradicional es realmente inmaterial o intangible?”. Catauro. Revista Cubana de Antropología 9: 99-107.

-. 2006. "Nuevos sitios de memoria del legado africano en Cuba". Consultado el 15 de noviembre del 2016. www.archivocubano.org/pdf/legado_africano.pdf.

Guillén, Nicolás. (1979) 1996. Obras completas (1920-1958). La Habana: Letras Cubanas.

Halbawchs, Maurice. 2011. La memoria colectiva. Buenos Aires: Miño Dávila.

Hale, Charles. 2014. "Entre lo decolonial y la formación racial: luchas afro-indígenas por el territorio y por (¿o en contra de?) un nuevo lenguaje contencioso”. Cuadernos de Antropología Social 40: 9-37.

Hall, Stuart. 2010. Sin garantías. Trayectorias y problemáticas en estudios culturales. Popayán; Lima; Bogotá; Quito: Envión Editores; Instituto de Estudios Peruanos; Universidad Javeriana; Universidad Andina Simón Bolívar, sede Ecuador.

Hill, Jonathan D. 1992 “Contested Pasts and the Practice of Anthropology”. American Anthropologist 94 (4): 809-815.

"Informe del Comité Nacional de Cuba de la Ruta del Esclavo". Unesco. Consultado el 15 de noviembre del 2016. www.lacult.org/docc/Cte_Cub_R_E_Info_2013.pdf.

Kush, Rodolfo. 1999. América profunda. Buenos Aires: Biblos.

Lafuente, Antonio y Alberto Corsín. 2012. “Comunidades de afectados, procomún y don expandido”. En El retorno de los comunes, coordinado por Carlos López Beltrán, 17-42. Ciudad de México: Conaculta. http://digital.csic.es/bitstream/10261/29806/1/procomun_don_expandido.pdf.

Lao-Montes, Agustín. 2007. "Decolonial Moves: Trans-Locating African Diaspora Spaces”. Cultural Studies 21 (2-3): 309-338.

Marrero Cruz, Eduardo. 2006. Don Julián de Zulueta y Amondo, promotor del capitalismo en Cuba. La Habana: Unión.

Matos, José. 2012. “Afrocubanía y políticas públicas”. En Afropolíticas en América del Sur y el Caribe, editado por Milena Annecchiarico y Alicia Martín, 33-56. Buenos Aires: Puentes del Sur. 
Mignolo, Walter. 2007. La idea de América Latina. La herida colonial y la opción decolonial. Barcelona: Gedisa.

—. 2010. Desobediencia epistémica: retórica de la modernidad, lógica de la colonialidad y gramática de la descolonialidad. Buenos Aires: Ediciones del Signo.

Millán, Saúl. 2004. “Cultura y patrimonio intangible: contribuciones de la antropología”. En Patrimonio cultural oral e inmaterial. La discusión está abierta. Antología de textos, editado por Bruno Aceves, 55-70. Ciudad de México: Consejo Nacional para la Cultura y las Artes, Coordinación de Patrimonio Cultural, Desarrollo y Turismo.

Moore, Carlos. 2008. Pichón: Race and Revolution in Castro’s Cuba. Chicago: Lawrence Hill Books.

Morales, Esteban. 2012. La problemática racial en Cuba. Algunos de sus desafíos. La Habana: José Martí.

Moreno Fraginals, Manuel. (1974) 2001. El ingenio. Complejo económico social cubano del azúcar. La Habana: Crítica.

Ortiz, Fernando. (1916) 1996. Los negros esclavos. La Habana: Editorial Ciencias Sociales.

—. (1940) 1963. Contrapunteo cubano del tabaco y del azúcar. La Habana: Consejo Nacional de Cultura.

—. (1950) 2001. La africanía de la música folklórica cubana. La Habana: Letras Cubanas.

Pollack, Maurice. 1989. “Memória, esquecimento, silencio”. Estudos Históricos 2 (3): 3-15.

Quiñones, Tato. 2009. “Nota dirigida al director del periódico Granma”. Afro Cuba, 21 de octubre. Consultado el 10 de octubre del 2016. http://afrocubaweb.com/coneg/cartagranma10-09.htm.

Restrepo, Eduardo. 2004. Teorías contemporáneas de la etnicidad: Stuart Hall y Michel Foucault. Popayán: Universidad del Cauca.

—. 2012. Intervenciones en teoría cultural. Popayán: Universidad del Cauca.

Romay, Zuleica. 2015. Cepos de la memoria. Impronta de la esclavitud en el imaginario social cubano. Matanzas: Ediciones Matanzas.

Rotman, Mónica. 2001. "Legitimación y preservación patrimonial: la problemática de las manifestaciones culturales 'no consagradas'”. En Memorias, identidades e imaginarios sociales, 154-168. Temas de Patrimonio 5. Buenos Aires: Comisión para la Preservación del Patrimonio Histórico Cultural de la Ciudad de Buenos Aires.

Sawyer, Mark Q. 2006. “'Introduction’: Race Cycles, Racial Hierarchy, and Inclusionary Discrimination: A Dynamic Approach”. En Racial Politics in Post-Revolutionary Cuba, 1-12. Cambridge: Cambridge University Press.

Segato, Rita L. 2007. La nación y sus otros: raza, etnicidad y diversidad religiosa en tiempos de políticas de la identidad. Buenos Aires: Prometeo.

Trouillot, Rolph-Michel. 1995. Silencing the Past. Power and the Production of History. Boston: Beacon Press. 
Turner, Victor. 1986. Dal rito al teatro. Bolonia: Il Mulino.

Unesco. 2010. "La Ruta del Esclavo. Reconciliar el deber de verdad con la memoria histórica”. París, Unesco. Consultado el 15 de noviembre del 2016. http://unesdoc.unesco.org/ images/0018/001866/186636s.pdf.

—. 2014. "La Ruta del Esclavo: 1994-2014. El camino recorrido". Consultado el 15 de noviembre del 2016. http://unesdoc.unesco.org/images/0022/002284/228475s.pdf.

Valdés Bernal, Sergio. 2000. "Los chinos desde el punto de vista lingüístico". En Catauro. Revista Cubana de Antropología 1 (2): 50-73.

Valero, Silvia. 2011. "Mapeando las narrativas de la diáspora en Cuba: la imaginación de la negritud en la literatura de entre siglos”. Revista Casa de las Américas 264: 93-105.

Vich, Víctor y Virginia Zabala. 2004. Oralidad y poder. Herramientas metodológicas. Bogotá: Norma.

Villegas Zulueta, Ana Rosa, Anselmo Villegas Zulueta, Eneida Villegas Zulueta, E. Sheleg, J. E. Blázquez y J. Diviñó Puyáns. 2013a. "Los negros y los blancos del ingenio y central azucarero Álava, sus sociedades e historia”. Actas del XIII Taller de Antropología Cultural y Social Afroamericana. La Habana: Casa de África. CD-ROM.

—. 2013b. "La sala museo del ingenio Álava hoy Central México en el trabajo social comunitario con niños y jóvenes”. Actas del XIII Taller de Antropología Cultural y Social Afroamericana. La Habana: Casa de África. CD-ROM.

Wade, Peter. 2010. “La presencia de 'lo negro' en el mestizaje”. En Mestizaje, diferencia y nación. Lo "negro" en América Central y el Caribe, coordinado por Elizabeth Cunin, 107-127. Ciudad de México: Instituto Nacional de Antropología e Historia.

Williams, Raymond. 2000. Marxismo y literatura. Barcelona: Península.

Yúdice, George y Toby Miller. 2002. Política cultural. Barcelona: Gedisa.

Zurbano, Roberto. 2012. "Cuba: doce dificultades para enfrentar al (neo)racismo o doce razones para abrir el (otro) debate”. Revista de la Universidad de La Habana 273: 266-277. 